\title{
PLATAFORMA MOODLE COMO FERRAMENTA EFICAZ NA ELABORAÇÃO DE CURSO BÁSICO DE PORTUGUÊS COMO LÍNGUA ESTRANGEIRA
}

\author{
PLATAFORMA MOODLE COMO HERRAMIENTA EFICAZ EN LA \\ ELABORACIÓN DE CURSO DE PORTUGUÉS COMO LENGUA EXTRANJERA
}

\author{
MOODLE PLATFORM AS NA EFFECTIVE TOOL IN PREPARING A BASIC \\ PORTUGUESE AS A FOREIGN LANGUAGE COURSE
}

\author{
Eduardo Rodrigues GOES ${ }^{1}$ \\ Letícia Bonesso GOMES ${ }^{2}$ \\ Regiani Aparecida Santos ZACARIAS ${ }^{3}$
}

RESUMO: A pesquisa, ora em desenvolvimento, propõe analisar a plataforma MoodleUnesp em um curso on-line de português como língua estrangeira (PLE). A plataforma Moodle é um Ambiente Virtual de Aprendizagem (AVA) que permite, dentre tantas ações, a criação e o gerenciamento de cursos, viabilização de material didático e avaliações de alunos. A interação no ambiente virtual pode ser criada por atividades propostas pelo professor (administrador) usando as ferramentas disponíveis nos campos "Atividades" e "Recursos", disponibilizados na plataforma. Da mesma forma, a associação de ferramentas dos campos "Atividades" e "Recursos" com materiais didáticos digitais e procedimentos adequados para o ensino de Português como língua estrangeira (PLE) são apresentados. Os resultados revelam que os módulos do MoodleUnesp permitem inserir grande variedade de tarefas e conteúdo em diferentes formatos, para o desenvolvimento das habilidades de fala, escrita, audição, leitura e cultura comprovando, assim a eficácia da plataforma no ensino de PLE.

PALAVRAS-CHAVE: Plataforma Moodle. Português como Língua Estrangeira (PLE). Ensino on-line.

RESUMEN: La investigación que se está desarrollando propone analizar la plataforma Moodle-Unesp en un curso en red de portugués como lengua extranjera (PLE). La plataforma Moodle es un Ambiente Virtual de Aprendizaje (AVA) que permite, entre sus muchas acciones, la creación y la administración de cursos, tornar viable material didáctico y evaluación de alumnos. La interacción en el ambiente virtual puede ser creada por actividades propuestas por el profesor (administrador) a partir del uso de las herramientas disponibles en los campos "Actividades" y

\footnotetext{
1 Universidade Estadual Paulista (Unesp), Assis - SP - Brasil. Graduado em Letras. Professor da Educação Básica. E-mail: eduardo_goes@outlook.com.

${ }^{2}$ Universidade Estadual Paulista (Unesp), Assis - SP - Brasil. Graduanda no Curso de Letras. E-mail: leticiabonessog@gmail.com.

3 Universidade Estadual Paulista (Unesp), Assis - SP - Brasil. Professora Doutora Assistente do Departamento de Letras Modernas da FCL-Assis. Ensino de línguas estrangeiras e lexicografia bilíngue pedagógica. E-mail: reca.zacarias@gmail.com.
} 
"Recursos", disponibles en la plataforma. De la misma forma, la asociación de herramientas de los campos "Actividades" y "Recursos" con materiales didácticos digitales y procedimientos adecuados para la enseñanza de Portugués como Lengua Extranjera (PLE) son presentados. Los resultados revelan que los módulos del MoodleUnesp permiten insertar gran variedad de tareas y contenido en diferentes formatos, para el desarrollo de las habilidades de habla, escrita, audición y cultura comprobando, así, la eficacia de la plataforma en la enseñanza de PLE.

PALABRAS CLAVE: Plataforma Moodle. Portugués como Lengua Extranjera (PLE). Enseñanza en red.

ABSTRACT: The research, currently in development, proposes to analyze the platform Moodle-Unesp in an online course of Portuguese as a foreign language (PLE). The Moodle platform is a Virtual Learning Environment (AVA) that allows, among many actions, the creation and management of courses, feasibility of didactic material and student evaluations. The interaction in the virtual environment can be created by activities proposed by the teacher (administrator) using the tools available in the "Activities" and "Resources" fields, available in the platform. Likewise, the association of tools of the "Activities" and "Resources" fields with digital didactic materials and adequate procedures for the teaching of Portuguese as a foreign language (PLE) are presented. The results show that the Moodle-Unesp modules allow the insertion of a wide variety of tasks and content in different formats for the development of speech, writing, listening, reading and culture skills, thus demonstrating the effectiveness of the platform in teaching PLE.

KEYWORDS: Platform Moodle. Portuguese as a Foreign Language (PFL). Teaching on-line.

\section{Introdução}

O interesse por cursos de PLE (Português como língua estrangeira) e pela cultura brasileira cresceu consideravelmente nos últimos anos, segundo a entrevista de Edleise Mendes, presidente da Sociedade Internacional de Português Língua Estrangeira (SIPLE) (PLATAFORMA MACAU, 2014). Uma das soluções que podemos encontrar para dar conta dessa demanda e quebrarmos barreiras de tempo e espaço é oferecermos cursos sobre este tema por meio da plataforma Moodle. Esta tecnologia foi criada pelo australiano Martin Dougiamas em 1999; caracteriza-se por ser um Sistema Open Source de Gerenciamento de Cursos - Course Management System (CMS), ou como dizemos em português, Ambiente Virtual de Aprendizagem (AVA). De acordo com Alexandre Farbiaz e Jackeline Farbiaz (2010): 
Os ambientes virtuais de aprendizagem são sistemas computacionaisplataformas- desenvolvidas por empresas ou instituições de ensino e caracterizam-se por possuírem dois componentes: o computacional e o pedagógico. Estes ambientes permitem o gerenciamento de cursos e atividades; o acompanhamento da trajetória dos alunos durante o curso; a publicação de conteúdos, atividades e avaliações; o acesso aos conteúdos; reunião de alunos e professores em turmas e a utilização de diversas ferramentas de comunicação e outras funcionalidades. (FARBIAZ A.; FARBIAZ J., 2010)

Logo, o Moodle foi desenvolvido para educadores criarem cursos on-line ou complementares aos cursos presenciais. Assim, os professores podem criar, administrar e moldar um curso segundo as suas necessidades e a área do conhecimento em que atuam.

Neste artigo apresentamos, primeiramente, as características principais do Moodle e os aspectos de sua funcionalidade que o tornam uma ferramenta de efetivo potencial interativo. Em seguida, revelaremos como se dá a criação de um curso Moodle e destacaremos a utilização do sistema Moodle para o ensino online de PLE.

\section{A plataforma Moodle}

Esta plataforma é um software gratuito utilizado por diversas instituições no mundo todo e é também a ferramenta escolhida pela Unesp (Universidade Estadual Paulista) para a educação a distância. Neste artigo ressaltamos algumas características da versão utilizada pela Unesp, a versão 2.5 , que por seu valor educativo e interface simples e amigável tornou-se um efetivo recurso para a modalidade de EAD (Ensino a distância), na referida instituição. A primeira versão do Moodle, criada por Martim Dougiamas, graduado em informática e também em educação, foi lançada em 1999. Se observarmos esta data de lançamento podemos pensar que esta plataforma é um software antigo e ultrapassado, no entanto, existem muitos técnicos que trabalham constantemente para aperfeiçoar e criar novas versões do Moodle. Afinal, o desenho modular desse software permite a evolução rápida de suas funcionalidades.

A plataforma em estudo, como já foi dito, por ser um ambiente virtual de aprendizagem "permite integrar múltiplas mídias, linguagens e recursos, apresentar informações de maneira organizada, desenvolver interações entre pessoas e objetos de conhecimento, elaborar e socializar produções tendo em vista atingir determinados objetivos". (ALMEIDA, 2003, p. 5). Assim, o professor, interessado em desenvolver um curso on-line de PLE via Moodle e realizar todas as atividades mencionadas acima, 
deve conhecer e dominar o campo 'Atividades' e 'Recursos' e utilizar suas ferramentas para "alimentar" o curso. Estes campos apresentam as seguintes ferramentas:

Atividades:

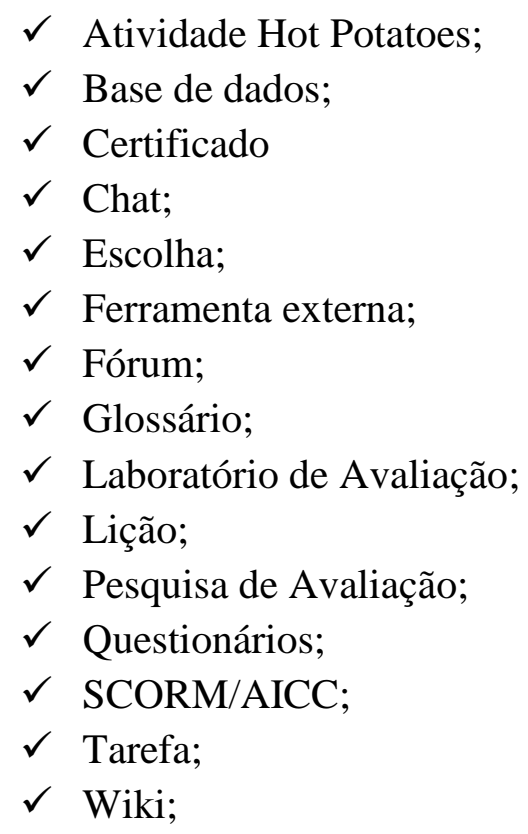

Recursos:

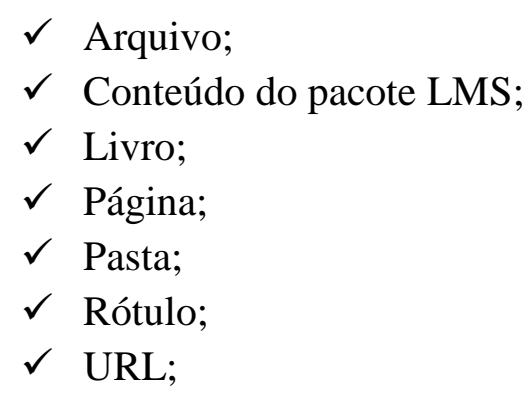

As ferramentas elencadas permitem ao professor inserir, solicitar e receber conteúdo didático-pedagógico. O campo 'Recurso' tem como objetivo permitir a disponibilização de conteúdo teórico como livros, arquivos, sites dentre outros, para serem estudados ou consultados pelo aluno. O campo 'Atividades' também permite a disponibilização de conteúdo, mas sua característica principal é propor a produção de diversos tipos de tarefas. Nesse campo podem ser utilizadas ferramentas para avaliação, comunicação e também outros recursos como glossários, diários, enquetes etc.

O Moodle foi desenvolvido a partir da teoria do Construtivismo. Esta concepção que deriva principalmente das teorias da epistemologia genética de Jean Piaget, sustenta a ideia de que o conhecimento é algo construído através das interações entre sujeito e o meio ambiente (PIAGET, 1978). Portanto, o professor do curso desenvolve as 
atividades de PLE através das ferramentas apresentadas acima. O aluno, por sua vez, interage com os conteúdos e com os integrantes, realiza as tarefas solicitadas e quando for o caso, as envia para o professor. Como resultado desses procedimentos haverá a produção de conhecimentos relacionados com os processos superiores de comunicação, linguagem e raciocínio.

\section{Papel do aluno e do professor}

Em um ambiente virtual de aprendizagem o aluno passa a ter um papel central na aprendizagem e tem a vantagem de escolher um horário de sua preferência para sentar-se em frente ao computador e realizar as tarefas estipuladas. Mas, ao mesmo tempo em que o aprendiz desfruta de autonomia, ele também estará inserido em um processo colaborativo que pressupõe responsabilidades como:

participação ativa do aluno no processo de aprendizagem; mediação da aprendizagem feita por professores e tutores; construção coletiva do conhecimento, que emerge da troca entre pares, das atividades práticas dos alunos, de suas reflexões, de seus debates e questionamentos; interatividade entre os diversos atores que atuam no processo; estimulação dos processos de expressão e comunicação; flexibilização dos papéis no processo das comunicações e das relações a fim de permitir a construção coletiva do saber; sistematização do planejamento, do desenvolvimento e da avaliação das atividades; aceitação das diversidades e diferenças entre alunos; desenvolvimento da autonomia do aluno no processo ensino-aprendizagem; valorização da liberdade com responsabilidade; comprometimento com a autoria; valorização do processo e não do produto (TORRES, 2004, p. 50)

O professor ou administrador, interessado em criar o curso, acompanha as atividades dos alunos, podendo estipular datas para a realização das tarefas, fornecer feedbacks e avaliar o ensino e aprendizagem do conteúdo de PLE, por meio das ferramentas do campo 'Atividades' e 'Recursos'. Por esta razão, o professor, para realizar seu trabalho, deve conhecer as funcionalidades e ferramentas da plataforma Moodle e, assim, associá-las ao ensino de língua, no caso, o português. Esta etapa é muito importante, pois, a aprendizagem em um ambiente virtual requer do aluno e do professor habilidades diferentes daquelas usadas, normalmente, em sala de aula em curso presencial de língua estrangeira.

\section{Moodle e a criação de um curso de PLE para iniciantes.}


Aprender um novo idioma é algo que ultrapassa as perspectivas da morfologia e da sintaxe, pois através da linguagem são reveladas as condições de vida do homem em sociedade. Considerando que a língua é um sistema que se desenvolve em realizações histórico-sociais e culturais, ensinar línguas é, portanto, revelar um povo, uma identidade, uma história, uma economia, enfim, mostrar toda uma sociedade e seus desdobramentos é descobrir uma nova cultura. Desta forma, por meio do uso da plataforma Moodle, podemos mostrar todo esse universo linguístico, cultural e social por meio de imagens, vídeos, jogos, áudios, músicas, textos, e hipertextos etc. Da mesma forma, deve-se contemplar as abordagens socioconstrutivista e sociointeracionista para que aluno participe ativamente na construção de seu conhecimento.

Definidas as abordagens, deve-se refletir sobre as características da língua portuguesa que se pretende ensinar e elaborar o plano de curso. Devemos ressaltar que no curso de PLE para iniciantes é importante trabalhar com a parte fonética e fonológica. Apesar de aparentemente simples, algumas vezes a não compreensão da fonética e fonologia da língua pode acarretar problemas para o estrangeiro na aprendizagem tanto da parte escrita quanto da parte oral. Pois, existem sete fonemas vocálicos multiplicados em muitos alofones tornando assim, "a realidade da língua oral muito mais complexa do que dá a atender o uso propriamente simples e regular das cinco letras latinas vogais da escrita". (CÂMARA JR, 2011, p. 39).

Assim como em um curso presencial, o criador do curso deve ter em mente quais abordagens, métodos e técnicas melhor colaboram para o processo de ensino e aprendizagem para assegurar que os objetivos pré-estabelecidos sejam alcançados. Deve-se também considerar o nível, a faixa etária, a linguagem materna e os conhecimentos linguísticos. Tendo em vista que o Moodle é um ambiente interativo, consideramos que abordagem Comunicativa, relacionada a contextos sociais e situações reais, pode ser amplamente explorada para o processo de aquisição de língua. Esta abordagem defende:

que a unidade básica da língua é o ato comunicativo ao invés da frase. O mais importante passa a ser o significado e não a forma. A competência comunicativa é o objetivo e não a memorização de regras. Para que essa competência ocorra, afirma-se que devem ser usadas situações do dia-a-dia dos alunos, assim eles conseguirão aprender as formas gramaticais percebendo que estas possuem utilidade e podem ser usadas no cotidiano. Além disso, poderão 
desenvolver as quatro habilidades da língua (audição, leitura, escrita e fala). (LIMA; SILVIA FILHO, 2013)

Segundo Leffa (2003), é importante que o professor siga algumas etapas para a produção dos materiais didáticos para o ensino de língua estrangeiras. Assim, de acordo com Leffa, para criar as atividades são necessárias algumas etapas, das quais destacaremos as fases:

1- Análise;

2- Definição dos objetivos;

3- Avaliação;

$\mathrm{Na}$ análise, o professor deve primeiramente definir o público alvo, ou seja, analisar quais são os interesses, anseios, necessidades dos alunos em relação à aprendizagem dessa nova língua. O nível de conhecimento do conteúdo desenvolvido, também deve ser considerado, pois "ninguém aprende algo que é totalmente conhecido e nem algo que seja totalmente novo" (LEFFA, 2003, p. 16). Portanto, parte do pressuposto que o aluno tem uma bagagem de vida e conhecimentos que são acionados em meio ao processo de aprendizagem.

Depois da análise feita é necessário definir os objetivos. Esta etapa é importante porque pode deixar claro o que o aluno pode esperar do curso e o que será cobrado dele, e para o professor, permite conseguir fazer uma avaliação, de forma mais precisa, do material elaborado e da evolução das habilidades de seu aluno. Os objetivos podem ser gerais ou específicos. Os objetivos gerais podem ser acompanhados de verbos como: "saber, compreender, interpretar, aplicar, analisar, integrar, julgar, aceitar, apreciar, criar" (LEFFA, 2003, p. 18). E existem os objetivos específicos que estão mais ligados com os resultados esperados para uma aula ou alguma atividade específica, e para esses objetivos os verbos que podem acompanhá-los são: "identificar, definir, nomear, relacionar, destacar, afirmar, distinguir, escrever, recitar, selecionar, combinar, localizar, usar, responder, detectar, etc.” (LEFFA, 2003, p. 18). Portanto, “o comportamento que o aluno deve demonstrar deve ser expresso por meio de um verbo que denota uma ação diretamente observável”. (LEFFA, 2003, p. 18)

Em relação à prática avaliativa, no contexto de EAD via Moodle, o professor pode disponibilizar tarefas com prazos de entrega, atribuir notas e depois trabalhar com revisões. Através de questionários feitos pelo módulo 'Escolha', entre outras 
ferramentas, o aluno pode avaliar sua própria interação com os conteúdos, com a própria plataforma e avaliar questões referentes ao conhecimento.

A escolha e a organização dos materiais pedagógicos são de extrema importância para o processo de ensino e aprendizagem, no entanto, outros fatores importantes devem ser desenvolvidos nos alunos para criar uma aprendizagem significativa. Estes fatores são: sensibilidade, motivação e relação afetiva (ROGERS, 1978). Então surgem as perguntas "Como criar uma relação afetiva entre os alunos e o professor? E como o professor pode motivar seus alunos em um curso a distância?" Dentro da própria plataforma estudada existe o "chat" que pode ser utilizado para desenvolver e estimular estas relações.

A criação do curso no Moodle envolve todo o processo de seleção dos recursos e criação das tarefas. Logo, para realizar estas tarefas mencionadas, o professor, deve clicar no botão "ativar edição" que se localiza na parte superior ao lado direito. E depois clicar em "adicionar a atividade ou recurso" e assim abrirá o campo "Atividades" e "Recursos". Desta forma, o professor pode selecionar a ferramenta que será usada para inserir e/ou criar a lição.

Figura 1: Campo 'Atividades e Recursos'.

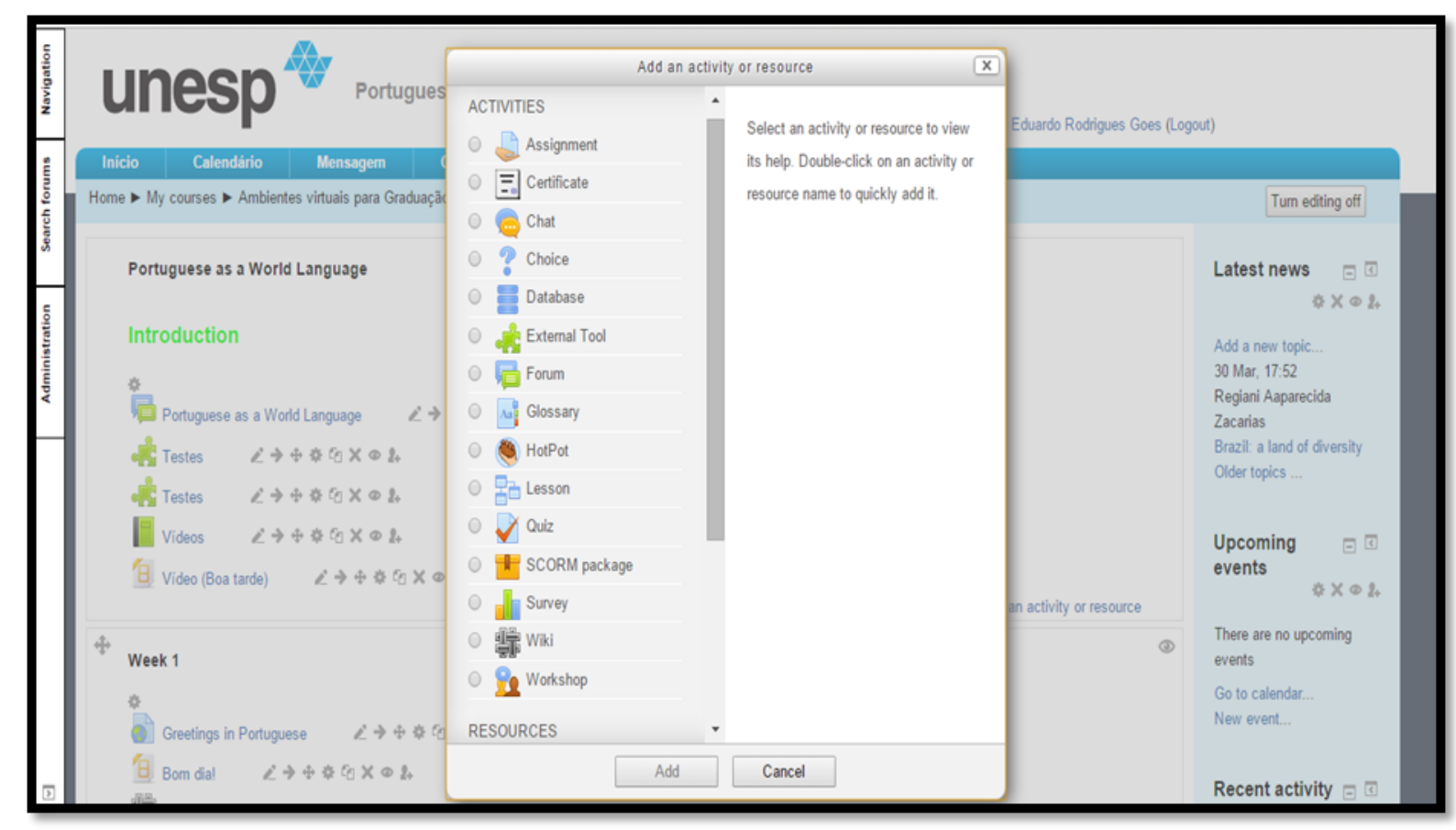

Fonte: Print screen da página do curso "Portuguese as a World language and Brazilian Culture. 
Assim, ressaltaremos a seguir algumas das funcionalidades das ferramentas disponíveis no campo "Atividades" e "Recursos" que permitem o ensino e aprendizagem de línguas, em especial, de PLE:

Chat- permite aos integrantes do curso manter uma interação síncrona e/ou assíncrona entre professor $\mathrm{x}$ aluno(s), aluno(s) x professor e aluno x aluno. $\mathrm{O}$ chat pode ser usado para discussão de ideias, conteúdos e dúvidas. Através do chat o aluno também tem a oportunidade de entrar em contato com os outros participantes, assim terá a oportunidade de enriquecer os seus conhecimentos interculturais. A comunicação pode ser realizada na língua estrangeira materna, ou quando possível, em português tornando-se assim, um espaço de comunicação real para os alunos interagirem e aplicarem seus conhecimentos.

Ferramenta externa: permite aos alunos acessarem e interagirem com recursos de aprendizagem de outros sites. A janela do site no qual o professor deseja que seu aluno visualize abrirá na própria interface do Moodle. Dessa forma, se o professor, por exemplo, desejar que seu aluno conheça informações sobre o exame do Celp-Bras (Certificado de Proficiência em Língua Portuguesa para Estrangeiros), a guia referente ao site desejado pode ser aberta da seguinte maneira:

Figura 2: Ferramenta externa.

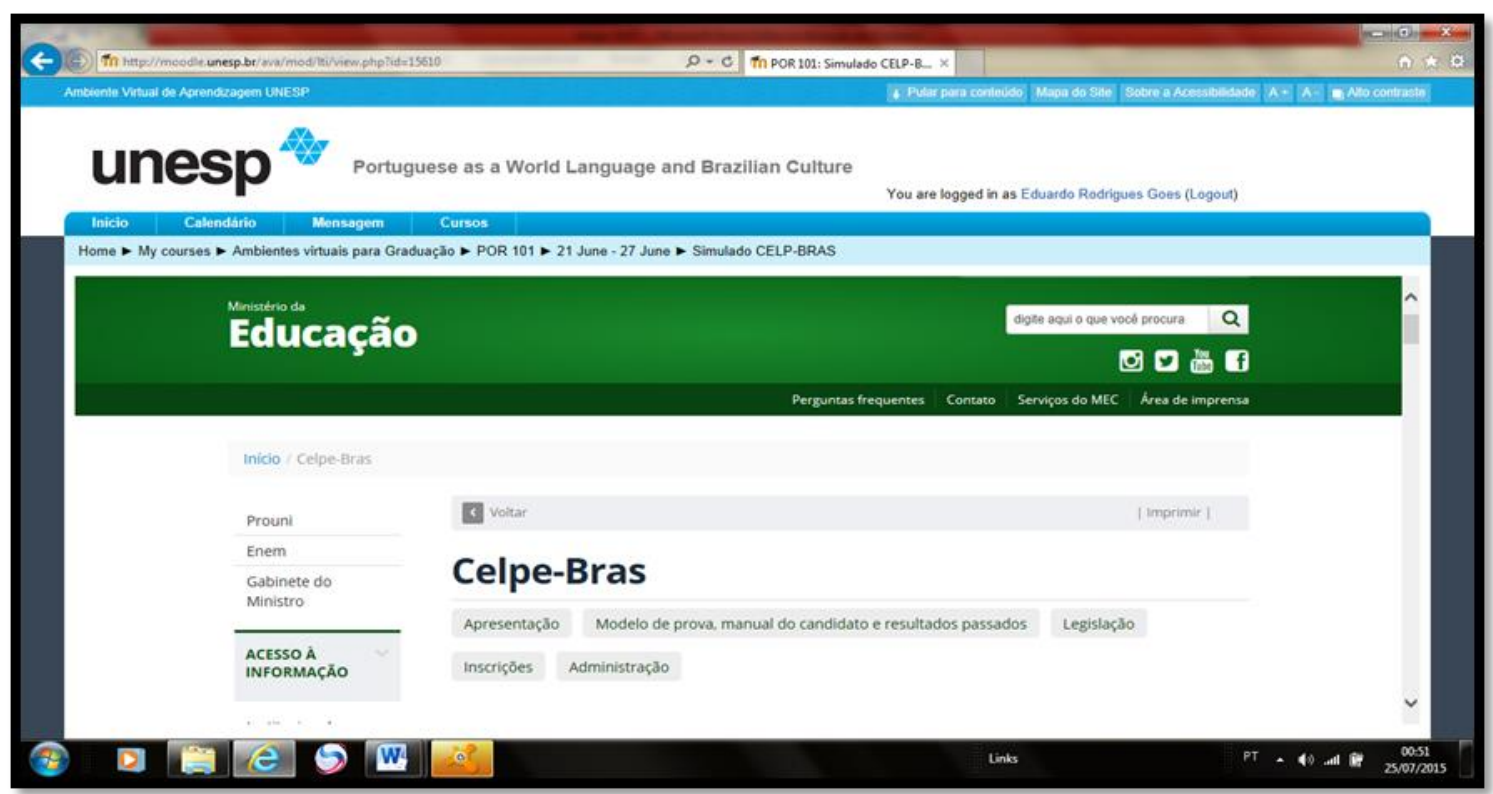

Figura 2: Ferramenta externa. Fonte: Print screen de informações sobre o exame do Celp-Bras através do site do Ministério da Educação por meio da plataforma Moodle.

Logo, podemos observar que não foi necessário abrir uma nova guia, dificultando assim à distribuição e visualização do site requisitado, pois o conteúdo 
desejado foi mostrado na própria plataforma, apesar de haver também a opção para abrir uma nova guia. Além disso, por meio dessa ferramenta cria-se um relacionamento entre o seu curso e o site visitado, pois o administrador deste site consegue verificar, individualmente, se seus alunos ou outros interessados acessaram ou visitaram o site, e consegue também ter acesso ao nome do curso e da Universidade, se for o caso.

Glossário: Pode ser usado para criar um glossário do conteúdo em estudo ou de alguma parte específica. $\mathrm{O}$ professor pode ser o único a ter acesso para inserir os vocábulos e editá-los, ou pode também permitir que os alunos participem da criação dessa ferramenta de aprendizagem. Os glossários podem ser agrupados e vistos em diferentes formatos, desta forma, o participante do curso poderá procurar as palavras por:

$\checkmark \quad$ Ordem alfabética: permite visualizar e pesquisar os vocábulos inseridos em ordem alfabética.

$\checkmark$ Categoria: O professor deve criar as categorias e, quando for inserir uma nova palavra (entrada), deve selecionar e classificar em uma das categorias criadas. Por exemplo, é possível criar uma categoria de alimentos e inserir palavras referentes à comida...

$\checkmark$ Data: permite visualizar as palavras em ordem cronológica desde a primeira palavra inserida até a última.

Autor: permite verificar uma lista de vocábulos que cada integrante inseriu. No processo de adicionar uma nova palavra-entrada no glossário, existem as possibilidades de inserir mídia, imagens, vídeos, áudios, etc.

Se o filtro de auto-linking glossário está habilitado, as entradas serão ligadas automaticamente onde as palavras e/ou frases conceito aparecerem dentro do curso.

Questionário - permite criar uma série de questões a respeito do conteúdo abordado, no qual, em seu processo de composição, o professor também pode inserir imagens, vídeos, áudios, gráficos, textos e etc. As possibilidades de configurações para as questões podem ser de:

\section{$\checkmark$ Verdadeiro/falso \\ $\checkmark$ Combinação/Associação \\ $\checkmark$ Respostas numéricas}




\section{$\checkmark$ Questões dissertativas \\ $\checkmark$ Questões randômicas (aleatórias)}

O administrador pode fornecer feedbacks automáticos e também pode configurar o número máximo de tentativas para o participante responder as perguntas. Em relação à avaliação, com exceção das questões dissertativas (essays questions), as notas de cada tentativa são salvas automaticamente e são registradas no livro de notas (gradebook). Além de tudo isso, os questionários são salvos por categoria em uma base de dados e podem ser reutilizados em outros cursos. Assim, basta o professor usar sua imaginação e criar suas perguntas sobre os mais diversificados temas. Em relação às questões dissertativas, estas constituem uma ótima oportunidade para criar perguntas com retornos (feedbacks) que não tenham o foco em uma única resposta pronta e acabada. Em outras palavras, o professor pode visualizar e avaliar e só depois dar um retorno, ou pode também escrever na parte "Descrição da atividade" que o sistema apresentará um feedback, mas que o foco do exercício será fazer com que o aluno aplique seus conhecimentos e desenvolva sua capacidade comunicativa na escrita, ou seja, não é necessário apresentar exatamente o que foi mostrado na resposta.

Tarefa- Este módulo permite ao professor pedir uma tarefa e depois atribuir diferentes tipos de feedbacks notas e comentários. Esta tarefa pode ser a realização de uma pesquisa, a escrita de algum texto ou um pedido de uma gravação de áudio ou vídeo referente ao conteúdo estudado etc. $\mathrm{O}$ aluno então poderá submeter (postar) qualquer tipo de material digital, com tamanho máximo de $15 \mathrm{MB}$, como por exemplo, documentos, planilhas, imagens, vídeos, textos em diferentes tipos de formatos como Word Excel, Adobe reader, PDF, entre outros. O professor pode estipular, através do sistema, uma data limite para as tarefas serem submetidas. O que mais chama a atenção nesse módulo, pensando no ensino de línguas, é o fato de permitir ao professor a possibilidade de acompanhar e avaliar a pronúncia, dicção entonação, enfim as facilidades e as dificuldades dos alunos na fala.

Escolha: Este módulo é usado para fazer enquetes e pesquisa de opinião. Então, o professor cria uma pergunta com respostas de múltipla-escolha. Vamos citar um exemplo:

O professor pensa em cinco temas sobre cultura brasileira e pede para seus alunos escolherem um entre eles para realizar uma pesquisa. Então ele cria a enquete e 
dá a oportunidade aos alunos de escolherem o assunto de maior interesse, dando a eles abertura para participar do direcionamento do curso.

Dentre as possibilidades de formatação do questionário é interessante saber que o professor tem a opção de:

$\checkmark$ Permitir ao aluno alterar a sua escolha, no caso do aluno ter mudado de ideia.

$\checkmark$ Escolher quantos estudantes poderão escolher uma determinada opção.

$\checkmark$ Aceitar respostas apenas em um período estipulado. O professor deve lembrar-se de citar essa informação na parte de descrição para que o aluno tenha acesso a essa informação e assim, possa responder o questionário.

Em relação aos resultados obtidos com a enquete, existem também as opções de:

$\checkmark$ Não publicar os resultados aos estudantes.

$\checkmark$ Mostrar os resultados ao estudante só depois que ele tiver dado a sua resposta.

$\checkmark$ Mostrar resultados após o fechamento do período de escolha.

$\checkmark$ Mostrar sempre os resultados aos estudantes.

Fórum: é um espaço virtual colaborativo que deve ser criado para discussões de algum conteúdo específico, no qual, neste contexto de ensino de PLE, pode abordar um tema relacionado à cultura brasileira. Assim, os participantes podem expressar suas opiniões e criar debates, tornando-se uma ferramenta de interação e comunicação. Além disso, pode contribuir para verificação de compreensão de leituras e também para avaliar a escrita, no caso da discussão ser feita em português. O fórum é uma ferramenta poderosa,

pois além de apresentar o encadeamento das discussões, identifica os autores das mensagens por meio da sua foto, que foi previamente inserida no seu perfil. Isto gera um maior sentimento de vínculo entre os alunos, já que personalizam a mensagem, diminuindo a sensação de estar conversando com a máquina. (TORRES; SILVA, 2014, p. 08). 
Livros: este módulo está inserido no campo "Recursos" e possibilita ao professor criar e editar um livro contendo diversos capítulos servindo como o material de leitura de conteúdos envolvendo as questões gramaticais e culturais da língua. No processo edição do livro, o professor pode incluir inúmeras imagens e vídeos. Em relação aos vídeos, o professor tem a opção de simplesmente inserir um vídeo encontrado na internet ou pode também produzir o seu próprio vídeo focando nos seus objetivos.

Hot Potatoes: é conjunto de seis programas de criação de páginas Web. Assim, o professor deve baixar o software Hot Potatoes no computador, criar as atividades e depois enviá-las para a plataforma. Este módulo permite a criação exercícios interativos, por meio dos seguintes tipos básicos:

$\checkmark$ JQUIZ: permite editar um texto apoio no próprio programa e depois criar questões de múltipla escolha. O professor de PLE pode trabalhar com diferentes gêneros textuais e depois criar suas questões para verificar a interpretação do texto.

$\checkmark$ JCloze: permite criar um exercício de preenchimento de texto através de lacunas, Nesta atividade o professor pode trabalhar com o foco em vocabulário, ou pode trabalhar com o foco na gramática, por exemplo, com os artigos definidos e indefinidos. Para facilitar para o aluno, o professor também pode criar pistas.

$\checkmark$ JCross: Permite criar palavras cruzadas podendo inserir o temporizador e pistas. O aluno, ao realizar esta atividade, estará aprendendo de forma lúdica, testando a sua memória em relação à aquisição de vocabulário.

$\checkmark$ JMix: é um exercício de frase desordenada.O aluno deve clicar em cada palavra para selecionar a ordem dos vocábulos e conseguir ordenar a frase. Esta atividade permite ao professor trabalhar com sintaxe e morfologia.

$\checkmark$ JMatch: Permite criar um exercício para ligar os respectivos elementos de duas colunas. Por exemplo, de um lado o professor pode distribuir o desenho de diferentes tipos de frutas e do outro lado distribuir a escrita de seus nomes de forma desordenada. Assim, o aluno deverá arrastar as palavras da coluna da direita para junto do elemento que lhes corresponde à esquerda. Dessa forma, o estudante estará aprendendo através de associação de imagens. 
A elaboração do plano de ensino e dos planos de aulas implica na seleção e muitas vezes, no caso do ensino online de línguas, na produção de material didático específico.

\section{Para além do curso}

Outra tecnologia que pode ser utilizada é o aplicativo de celular chamado de WhatsApp que permite o envio de mensagens escritas, áudios, fotos, figuras e vídeos. Por meio desse aplicativo, todos os integrantes do curso podem estar em constante comunicação e, portanto, poderão criar os laços afetivos e ainda terão a oportunidade de usar a língua estrangeira, no caso o português, em um ato de comunicação real e com dados linguísticos autênticos. Outra estratégia que pode ser adotada, segundo a abordagem Humanística é utilizar temas de interesse dos alunos e com isso, possibilitar a liberdade de expressão nas tarefas que envolvam a escrita e gravações de áudios e vídeos.

\section{Considerações finais}

Ao analisarmos e associarmos as funcionalidades das ferramentas selecionadas com alguns recursos, técnicas, estratégias relevantes para o ensino online de línguas, chegamos à conclusão de que a plataforma Moodle permite a criação de um curso de PLE capaz de desenvolver nos alunos todas as competências linguísticas para a aquisição de uma língua estrangeira. No entanto, devemos ressaltar que a comunicação através da fala, possa ser um processo menos desenvolvido, pois não há na própria plataforma Moodle uma ferramenta, que permita concretização do ato de fala em tempo real. Mas, tratando-se da modalidade de EAD, nada impede que o professor utilize outros recursos como o SKYPE, WhatsApp, dentre outros, para fornecer ao seu aluno um ensino de línguas de qualidade e eficaz.

Consideramos também que para criar, inserir, avaliar os conteúdos, atividades e tarefas, que serão produzidas referentes ao ensino e aprendizagem de PLE, o professor deve levar em conta tanto os aspectos tecnológicos quanto pedagógicos. Ou seja, o interessado em criar o curso deve estudar as funcionalidades da plataforma, os materiais didáticos que serão criados e /ou utilizados, e também as especificidades do ensino e aprendizagem de PLE nesta modalidade de ensino a distância. 
Portanto, qualquer profissional capacitado em ensino de PLE pode desenvolver seu curso via plataforma Moodle e levar a língua portuguesa, e com ela toda a riqueza cultural dos países lusófonos, a qualquer instituição ou pessoa interessada. Assim, concluímos que este Ambiente Virtual pode tornar-se uma ferramenta de grande potencial para o ensino de PLE online, pois oferece ao professor e aos alunos um ambiente virtual colaborativo, interativo e estimulante.

\section{REFERÊNCIAS}

ALMEIDA, M. E. B. Tecnologia e educação a distância: abordagens e contribuições dos ambientes digitais e interativos de aprendizagem. Educação e Pesquisa, São Paulo, v.29, n.2, p. 327-340, jul./dez. 2003. Disponível em:

<http://www.scielo.br/pdf/ep/v29n2/a10v29n2.pdf>. Acesso em: 20 jun. 2015.

BELLONI, M. L. Ensaio sobre a educação a distância no Brasil. Educação \&

Sociedade, abr. 2002, vol.23, n.78, p.117-148. Disponível em:

<http://www.scielo.br/pdf/es/v23n78/a08v2378.pdf>. Acesso em: 5 jan. 2015.

CAMARA JÚNIOR, J. M. Estrutura da língua portuguesa. 44 ed. Petrópolis, RJ:

Vozes, 2011.

FARBIARZ, A.; FARBIARZ, J. Reflexão acerca do design de ambientes virtuais de aprendizagem. Revista Tríades, out. 2010. Disponível em:

<http://www.revistatriades.com.br/blog/wp-content/uploads/2011/12/farbiarz_ok.pdf>. Acesso em: 12 jan. 2015.

LEFFA, V. J. Como produzir materiais para o ensino de línguas. In: LEFFA, V.J.

(Org.). Produção de materiais de ensino: teoria e prática. Pelotas: EDUCAT, 2003, p. 13-38. Disponível em: <http://www.leffa.pro.br/textos/trabalhos/prod_mat.pdf >. Acesso em: 05 jan. 2015.

PIAGET, J. O nascimento da inteligência na criança. Tradução: Álvaro Cabral. Rio de Janeiro: Zahar, 1978.

ROGERS, C. R. Liberdade para aprender. Trad. de Edgard de Godói da Mata Machado e Márcio Paulo de Andrade. 2ª ed. Belo Horizonte: Interlivros, 1973.

TORRES, A. A.; SILVA, M. L. R. O ambiente Moodle como apoio a educação a distância. In: $2^{\circ}$ Simpósio Hipertexto e Tecnologias na Educação, 2008. Anais eletrônicos. Disponível em:

<http://www.latec.ufrj.br/monografias/2009_Laura_delgado.pdf $>$. Acesso em: 15 jun. 2015.

TORRES, P. L. Laboratório on-line de aprendizagem: uma proposta crítica de aprendizagem colaborativa para a educação. Cad.CEDES, Campinas, v.27, n.73, 
set./dez. 2007. Disponível em: 〈http://www.scielo.br/pdf/ccedes/v27n73/06.pdf>. Acesso em: 17 mar. 2015.

VILAÇA, M. L. C. WEB 2.0 e materiais didáticos de línguas: reflexões necessárias. In: Cadernos do CNLF, vol. XV, no 5, t. 1. Rio de Janeiro: CiFEFiL, 2011. Disponível em: 〈http://www.filologia.org.br/xv_cnlf/tomo_1/90.pdf>. Acesso em: 18 jun. 2015.

\section{Sites consultados:}

BRASIL. Ministério da Educação. O que é educação a distância? Disponível em: $<$ http://portal.mec.gov.br/index.php?option=com_content\&view=article\&id=12823:0que-e-educacao-a-distancia\&catid=355\&Itemid=230> Acesso em: 10 jan. 2014.

MOODLE: Community driven, globally supported. Disponível em:

<https://Moodle.org/> Acesso em: 22 nov. 2013.

PLATAFORMA MACAU. Português gera interesse mundial "nunca visto".

Disponível em: <http://www.plataformamacau.com/macau/portugues-gera-interessemundial-nunca-visto/> Acesso em: 10 dez. 2014.

SÓ PORTUGUÊS: Português no mundo. Disponível em: <http://www.soportugues.com.br/secoes/portuguesMundo.php> Acesso em: 19 jan. 2014.

\section{Como referenciar este artigo}

GOES, Eduardo Rodrigues.; GOMES, Letícia Bonesso.; ZACARIAS, Regiani Aparecida Santos. Plataforma Moodle como ferramenta eficaz na elaboração de curso básico de português como língua estrangeira. Rev. EntreLínguas, Araraquara, v.3, n.1, p. 19-34, jan./jun. 2017. Disponível em: <https://doi.org/10.29051/rel.v3.n1.janjun.2017.9274>. E-ISSN: 2447-3529.

Submetido em: 24/01/2017

Aprovado em: 27/03/2017 